\title{
New laboratory tools in the assessment of bone quality
}

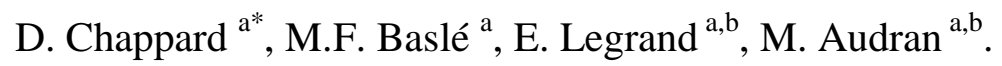

${ }^{a}$ INSERM, U922 - IRIS-IBS Intitut de Biologie en Santé, CHU d'Angers, 49933 ANGERS Cedex -FRANCE.

${ }^{\mathrm{b}}$ Rheumatology unit, CHU d'Angers, 49933 ANGERS Cedex -FRANCE.

e-mail: daniel.chappard@univ-angers.fr

doi: $10.1007 / \mathrm{s} 00198-011-1573-6$.

Key words: bone quality, bone microarchitecture, bone mineralization, microCT, FTIRI, Raman spectroscopy.

\section{Miniabstract}

Bone quality is a complex set of intricated and interdependant factors that influence bone strength. A number of methods have emerged to measure bone quality in the laboratory taking into account the organic or the mineral phase of the bone matrix.

\section{Abstract}

Introduction. Bone quality is a complex set of different factors that are interdependent. The bone matrix organization can be described at five different levels of anatomical organization: nature (organic and mineral), texture (woven or lamellar), structure (osteons in the cortices and arch-like packets in trabecular bone), microarchitecture and macroarchitecture. Any change in one of these levels can alter bone quality. An altered bone remodeling can affect bone quality by influencing one or more of these factors.

Here, we have reviewed the main methods that can be used in the laboratory to explore bone quality on bone samples. Bone remodeling can be evaluated by histomorphometry, microarchitecture is explored in 2D on histological sections and in $3 \mathrm{D}$ by microCT or synchrotron. Microradiography and scanning electron microscopy in the backscattered electron mode can measure the mineral distribution; Raman and Fourier transformed infra-red spectroscopy and imaging can simultaneously explore the organic and mineral phase of the matrix on multispectral images; scanning acoustic microscopy and nanoidentation provide biomechanical informations on individual trabeculae. Finally, some histological methods (polarization, surface staining, fluorescence, osteocyte staining) may also be of interest in the undestanding of quality as a component of bone fragility. 
Conclusion. A growing number of laboratory techniques are now available. Some of them have been described many years ago and can find a new youth, others having benefit from improvements in physical and computer techniques are now available.

$\begin{array}{ll}\text { Table 1: } & \text { main abbreviations used in the present review } \\ \text { DXA } & \text { Dual Energy bone densitometry } \\ \text { BMD } & \text { bone mineral density } \\ \text { BSU } & \text { bone structure unit } \\ \text { microCT } & \text { microcomputed tomography } \\ \text { pQCT } & \text { peripheral quantitative computed tomography } \\ \text { MRI } & \text { magnetic resonance imaging } \\ \text { SEM } & \text { Scanning electron microscopy } \\ \text { BSE } & \text { backscattered energy mode } \\ \text { BMDD } & \text { Bone Mineral Density Distribution } \\ \text { FTIR } & \text { Fourier transformed infra-red } \\ \text { FTIRI } & \text { Fourier transformed infra-red imaging } \\ \text { SAM } & \text { Scanning Acoustic Microscopy } \\ \text { AFM } & \text { Atomic Force Microscopy } \\ \text { FEA } & \text { Finite Element Analysis }\end{array}$

\section{Introduction}

Fragility fractures due to osteoporosis are frequent at the distal forearm, vertebrae and the hip. They occur commonly under non traumatic conditions and affect $\sim 30 \%$ of women after the menopause and $\sim 10 \%$ of men. Dual Energy bone densitometry (DXA) has become the most used non-invasive method to quantify the calcified bone mass at the hip and lumbar spine. However, the technique measures an areal bone mineral density (BMD) which is influenced by bone size; it cannot distinguish between cortical and trabecular bone and can be affected by several factors such as arthritis. In addition, a number of studies have reported that, although BMD explains a noticeable number portion of the fracture risk [1-2], there is a large overlap between BMD values of patients with and without fractures [3-6]. Furthermore, patients under long-term corticosteroid therapy have an increased risk of fracture than non treated osteoporotic patients with the same BMD [7]. Patients with increased bone density in Paget's disease of bone or osteopetrosis can also develop fragility fracture [8-9]. Osteoporotic patients undergoing a bisphosphonate therapy have a modest gain in BMD ( 5-8 \%) that do not explain the marked reduction in the number of fractures [10-12]. It is now clear that bone mass, as measured by BMD does not fully account for the bone fragility in metabolic bone diseases. When bone histomorphometry was the only method for measurement of bone mass (as expressed by a trabecular bone volume, BV/TV<11\%) [13], it also became evident that the amount of bone was not the unique factor to explain fragility: the first parameter of bone quality to be recognized was trabecular bone microarchitecture since $\sim 50 \%$ of post-menopausal women have a normal bone volume but altered trabecular bone descriptors with an increase of trabecular spacing due to perforations [14-15]. Bone quality remained during a long time as "anything that cannot measured". Recently bone quality was defined as "the sum total of characteristics of the bone that influence the bone's resistance to fracture" [16]. This term of "bone quality" has been used to describe a variety of factors known to influence bone strength; however the enumeration of these factors is complex since most of them are interdependent. As proposed by Felsenberg and Boonen, bone quality could be compared to "an umbrella term that describes the set of characteristics that influence bone strength" and interrelationships between them [17]. 


\section{Bone: a biomaterial with specific biomechanical properties}

Bone is a highly sophisticated connective tissue which exerts several tasks in the body: it is connected with muscles and thus has mechanical functions; it is the main reservoir of calcium, phosphate and sodium ions in the body; it is the host of the hematopoietic bone marrow and recent studies have identified its role in the regulation of energy metabolism [18]. If one except the case of the skull, bone strength is directly limited to the mechanical usage and, from the molecular level to the anatomical level, it is built to resist and adapt to strains [19-20]. Five main levels of organisation can be used to describe bone from an anatomical point of view (Figure 1) [21-22]:

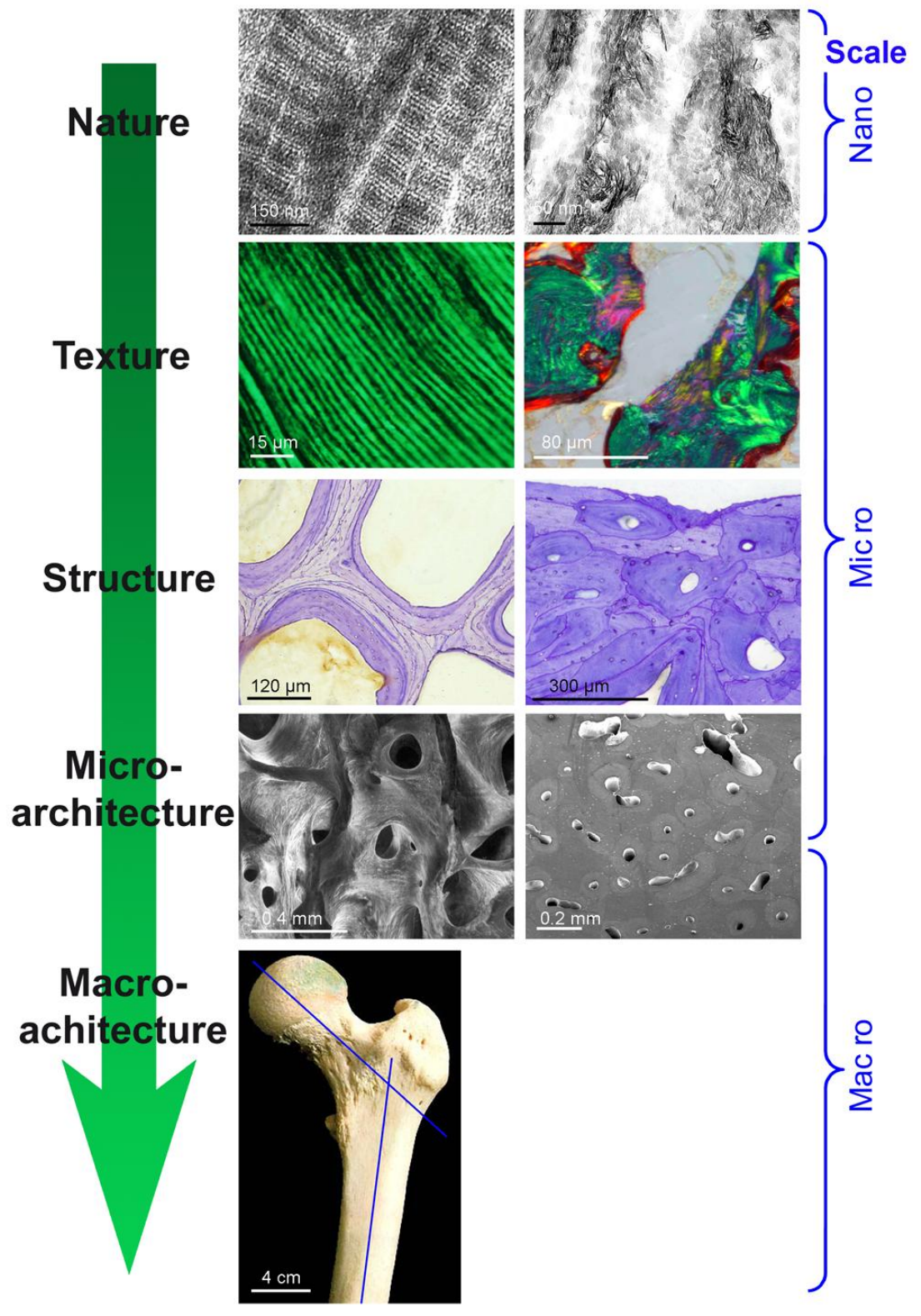

Fig. 1 The five anatomical levels of organisation of bone. The nature is composed of the organic phase of collagen fibers (left) and hydroxyapatite crystals (right) seen in transmission electron microscopy. The texture can be lamellar in mature bone (left) while woven bone is composed of randomly packed collagen bundles (right), polarization microscopy on Goldner stained sections. The structure is different in trabecular bone with arch-like BSUs (left) and in cortical bone with osteons centered on a Haversian canal (right), toluidine blue staining. Microarchitecture is also different in trabecular bone with plates and rods (left) and in cortical bone with compacted osteons (right), SEM. Macroarchitecture of bone 
(upper femoral extremity) with curvatures and angulations (blue lines on the neck and diaphyseal axes). Adapted from reference [22].

\section{1) The nature of bone: a double composition with an organic and a mineral phase}

\section{The organic phase}

Type I collagen is the most abundant protein which constitutes the organic phase of the bone matrix (90\% of total proteins) and is synthesized by osteoblasts. It is made of broad fibers composed of fibrils presenting a characteristic $67 \mathrm{~nm}$ transverse striation in electron microscopy. The type I collagen molecule comprises two identical $\alpha 1$ chains and one $\alpha 2$ chain ; they are coded by two different genes (respectively on chromosomes 17 and 7). Mutations in type I collagen genes (COL1A1 and COL1A2) cause osteogenesis imperfecta. However, new mutations that did not imply type I collagen have been encountered in the type V, VI and VII forms of osteogenesis imperfecta [23]. Post-translational changes of the collagen molecule have been found to decreased bone strength in patients with osteoporosis [24] and in recombinant congenic mice [25]. Osteoblasts synthesize molecules of procollagen whose telopeptides are cleaved extracellularly to assemble the collagen molecules. The C-terminal propeptide of type I collagen can be dosed to appreciate the activity of bone formation. The cross-links, which stabilize and reticulate collagen I molecules have been shown to strongly influence bone properties. Cross links depend of the enzymes lysine hydroxylase and lysine oxidase acting at specific Lys or Hyl residues. Different types have been described as immature reducible divalent cross-links (deH-DHLNL dehydro-dihydroxylysinonorleucine, deH-HLNL dehydrohydroxylysinonorleucine, deH-LNL dehydro-lysinonorleucine) and mature non-reducible trivalent cross-links ( $P Y D$ hydroxylysyl-pyridinoline, $D P D$ deoxy-pyridinoline, $P Y L$ pyrrololine and $D P L$ deoxypyrrololine [26-27]. Trivalent cross-links cannot be hydrolyzed by osteoclasts, their urinary dosage reflects the resorption activity. Collagen confers elastic and flexible properties to the bone matrix [24]. Alteration of collagen cross-links has been found in osteoporotic patients [28] or with low plasma homocysteine levels [29]. Advanced glycation end products (AGEs, non-enzymatic cross-links) accumulates with aging in bone collagen and have detrimental effect on bone strenght in in osteoporosis and diabetes [27].

Mutations in genes coding for non-collagenous proteins have also been found to induce considerable changes in genetically modified mice (e.g., matrix GLA protein, osteocalcin...). Noncollagenic proteins account for approximately $10 \%$ of total proteins of the bone matrix. More than 200 non-collagenic proteins have been identified. Some are synthesized by osteoblasts (75\%), the others are proteins conveyed by the serum and deposited in the bone matrix. The most abundant proteins are albumin, immunoglobulins, a $\alpha_{2}$-HS glycoprotein (fetuin), matrix gla protein, osteocalcin, osteonctin, alkaline phosphatase and several SIBLING proteins (Small Integrin Binding Ligand N-glycosylated Protein) such as osteopontin and bone sialoprotein which are used for cell adherence onto the matrix. For most of these non-collagenous proteins, their role is more or less well elucidated: $\alpha_{2}$-HS glycoprotein interferes with the mineralization [30] and is used as a storage molecule for certain growth factors (such as Transforming Growth Factor- $\beta$ ).

\section{The mineral phase}

The skeleton is the main reservoir of the body for calcium and phosphate. Bone acts as a storage bank for calcium in form of poorly crystalline hydroxyapatite tablets $\left(\mathrm{Ca}_{10}\left[\mathrm{PO}_{4}\right]_{6}[\mathrm{OH}]_{2}\right)$ with hydrogen phosphate $\left(\mathrm{HPO}_{4}\right)$, carbonate $\left(\mathrm{CO}_{3}\right)$ groups substituting for the phosphate ions. During aging, there is an increase in the carbonate, fluoride and calcium content with a reduction in 
hydrogen phosphate leading to an increase in the $\mathrm{Ca} / \mathrm{P}$ ratio [31]. The mineral phase is a high elastic modulus material deposited around and within the low elastic modulus organic collagen fibers; mineral stiffens the organic phase so the bone matrix is both viscoelastic and rigid [32]. A major characteristic of the bone matrix mineralization is its heterogeneity. Because the bone packets (BSU - bone structure units) are apposed at various periods (due to the remodeling cycles), all of them are not equally mineralized. Mineralization begins approximately 15 days after osteoblasts have deposited the collagen fibers and non-collagenous proteins to form osteoid seams. After osteoblasts have completely built a BSU, the mineralization process continues until the matrix is loaded with $70 \%$ of its capacity of hydroxyapatite within approximately 120 days (primary mineralization). After the cessation of osteoblasts' activity, calcification continues to process slowly during the secondary phase which can last years or decades (secondary mineralization) [33]. The final result is that bone is a heterogeneous material, when considering the mineralization degree, with BSUs of various calcification densities packed together. Hydroxyapatite in bone contains many impurities (carbonates, magnesium, acid phosphates, fluoride) and appears defective in hydroxyl radicals and calcium. When compared with geological apatites, it is a carbonate rich apatite, poorly crystallized. Hydroxyapatite is not deposited randomly in bone, it appears at the mineralization front in the form of small crystals, then calcification continues by increasing the size of the crystal and addition of new crystals between the collagen fibers [34].

\section{2) The texture of bone: a woven or lamellar arrangement of the matrix}

During remodeling, osteoblasts synthetize bone matrix by depositing collagen fibers in the form of superimposed lamellae. In these lamellae, collagen is oriented in a precise way with an angular change between each lamella. This is responsible for the characteristic appearance of bone texture in polarization microscopy with an alternance of dark and birefringent lamellae. When osteoblast activity is very high (fetal bone, fracture callus, microfractures, fibrous dysplasia, metaplastic bone in the bone metastasis, Paget's disease...) they synthetize a bone matrix with an anarchic texture in which collagen fibers have random directions. This is termed woven bone, or non-lamellar bone; its biomechanical properties are poorer than those of lamellar bone despite its higher degree of mineralization. The irregular collagen-fibril orientation and irregular pattern of mineralization make it capable to absorb less energy [35-36].

\section{3) The stucture of bone: osteon and arch-like Bone Structure Units}

The BSU shape is under the control of cell remodeling. At the time of the remodeling, a group of osteoblasts will synthetize a BSU. BSUs are different in the cortical and trabecular bone.

\section{- in the cortices}

The structural units consist of osteons (Haversian systems) with a cylindrical shape; they are centered around a canal. Typically, a complete osteon is $200-300 \mu \mathrm{m}$ in diameter with a central Haversian canal of $\sim 50 \mu \mathrm{m}$ in diameter. The walls of the osteon consist in concentric accumulation of lamellae. Inside the Haversian canal, blood-vessels and sympathetic nerve fibers can be observed. The Haversian canals are inter-communicating and branched; the transverse Volkmann's canals ensure the communication between them and allow the circulation between periosteal and endosteal spaces. Between complete osteons, incomplete remnants of old, partially eroded BSU constitute the interstitial bone.

\section{- in the trabecular bone}

BSUs are comparable to incomplete osteons with an arch-like appearance. In the young, some intratrabecular Haversian systems can be observed. These arch-like BSU are $\sim 40-45 \mu \mathrm{m}$ in thickness and represent a stacking of lamellae. New BSU are laid down onto trabecular surfaces 
that have been previously eroded by osteoclasts. Between the newly apposed BSUs, remnants of partially eroded ones persist and constitute the intersitital trabecular bone.

The organizational levels provides an increased mechanical resistance: if one considers cylinders made with the same amount of material, a hollow cylinder is much more resistant to bending than a solid one because resistance to bending increases in proportion to the $4^{\text {th }}$ power of the distance from the neutral axis [37]. Dysregulation of the bone structure can occur in a variety of pathologic situations: the best example is Paget's disease in which BSUs are composed of irregular packets with a puzzle appearance.

\section{4) The microarchitecture of bone}

The BSUs are packed together in order to form:

- dense bone, in the cortices where osteons are compacted so that the axes of Haversian canals run parallel with the resulting stress line which is exerted on the bone. Osteons are located in the cortex between the periosteal and endosteal surfaces composed of circumferential lamellae. Under the periosteum, the osteons layer is doubled by a number of parallel lamellae constituting the periosteal bone. In the same way, the osteons on the medullary side are covered by lamellae which compose the endosteal tissue. Transverse Volkman's canals cross these layers and anastomose transversely the Haversian canals.

- trabecular bone tissue, where the BSUs compose 2 different types of trabeculae: large plates (arranged along the stress lines) connected laterally by pillars or rods which ensure the cohesion of the network [14]. The role of trabecular bone is to resist to compression loads, and to transfer the strains to the cortices. The "plate and rod" appearance was rediscovered by Parfitt and brought a new vision on the mechanisms of bone loss in metabolic bone diseases. However, this characteristic appearance is variable according to the different bones but also with age: in the young, trabecular bone is more a honeycomb network; during ageing, the microarchitecture is remodeled, the rods become thinner and the plates more easily identifiable [38].

\section{5) The bone macroarchitecture.}

The size and shape of a bone have a direct effect on their strength. Bones have special angulations and curvatures which are genetically and epigenetically determined and enable them to resist to compression, tension or torsional (shearing stress) loads [39-40]. The most efficient way for resisting bending and shearing stress involves a distribution of the bony material far from the neutral axis. The geometry of bone considerably affects the distribution of strain and can constitute a risk for fracture, per se: the length of the femoral neck predisposes to fractures of the hip [41-42]. Similarly fractures are more frequent in patients with smaller vertebral bodies [43]. Differences in the diaphyseal diameter of long bones govern the main difference in bending strength between males and females. For vertebrae, BMD is similar in males and females at puberty but the size of the vertebral body itself is larger in males, allowing these bones to support a higher load during aging [44]. Other geometric factors such as the neck-shaft angle or the intertrochanter-head center distance could be of interest to appreciate this qualitative parameter at the hip [45-46].

\section{Laboratory techniques for measuring bone quality at the anatomical level}

In the pathogenesis of bone fragility, the ability of bone to resist fracture depends on bone mass, and the intrinsic properties of the bone material [47-48]. It is likely that the mechanicalany change in one of these levels of organization of the bone matrix can play a key role. Several of these factors have been identified and can now be measured in vitro on bone specimens, (e.g. 
bone biopsy), unfortunately, the number of in vivo systems that can explore bone quality, remains limited at the present time. In this review, we will not consider the different methods used to measure the geometry of bones. Measurements of orthopedic indexes, radiogrammetry of metacarpal bones or vertebrae [49] and texture analysis of X-ray images [50-51] are clinical tools that will not be detailed here. The following laboratory techniques have been developped over the last decades to explore one or more components of the quality of the bone matrix (abbrevations of the different methods appear in table1). As mentionned above, the various aspects controlling bone quality are highly linked together (figure 2). Bone remodeling (the sequential process consisting in resorption of "old" matrix by osteoclasts, followed by new BSU formation by osteoblasts) can interfere with a number of bone quality factors, including the nature, texture, structure and microarchitecture components of the bone matrix.

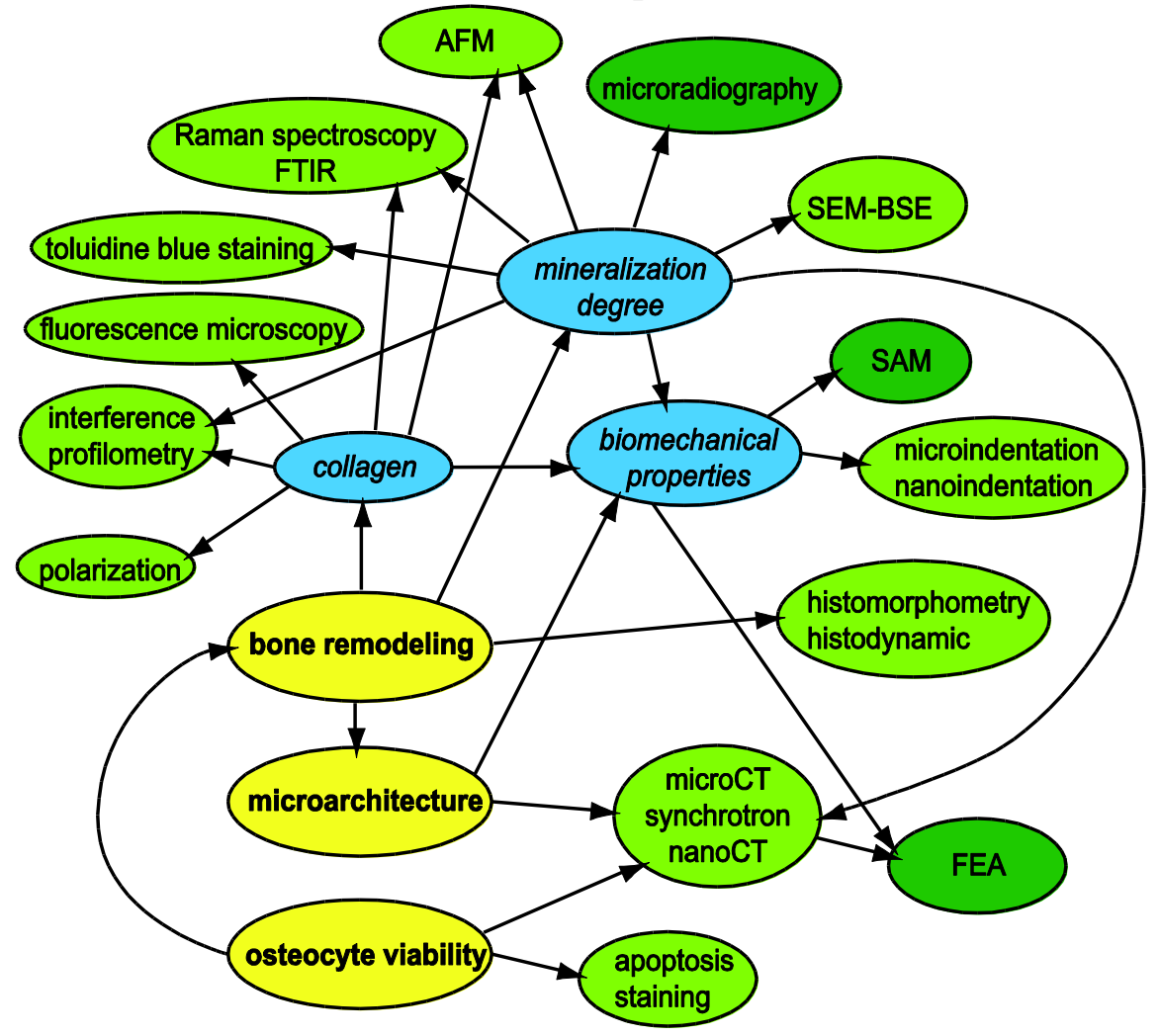

Fig. 2 The bone quality encompasses a number of highly intricated levels that interfere with each others. In white, the different techniques available that can investigate several aspects of bone quality.

\section{Bone histomorphometry: a direct measure of bone remodeling}

The technique was initially proposed to measure bone mass and bone cell activities. Double labeling with fluorochromes (tetracycline in man, calceine, alizarine red, xylenol orange... in animals) represents a unique tool to measure the bone turnover by a non radioactive method [52]. Bone mineralization rates in the cortical and trabecular envelopes can easily be determined and the bone formation rates can be derived; taken together, these parameters can fully describe bone formation activity in the trabecular bone. Similarly, identification of osteoclasts by histochemical demonstration of their tartrate resistant acid phosphatase content provides an accurate measure of their number which cannot reliably be obtained on standardly stained sections [53].

However, bone histomorphometry has gained a new interest when it became possible to measure trabecular microarchitecture. The first microarchitectural descriptors were available after the Parfitt's principles based on the "plate and rod" model. Trabecular thickness, number and separation are now "basic" parameters that can be applied on other 2D images of trabecular bone 
such as microcomputed tomography (microCT), peripheral quantitative computed tomography (pQCT) or magnetic resonance imaging (MRI) images [14]. A number of attempts have been done to develop new methods which are not based on the "plate and rod" model. Several algorithms have been proposed that use new principles of mathematical morphology, image analysis and fractal geometry (Figure 3) [54-57]. It is now clear that microarchitecture of trabecular bone cannot be evaluated with a single parameter and several techniques must be used to describe the trabeculae, the marrow cavities, connectivity, anisotropy and 3D regularity of distribution of the trabecular network [21].
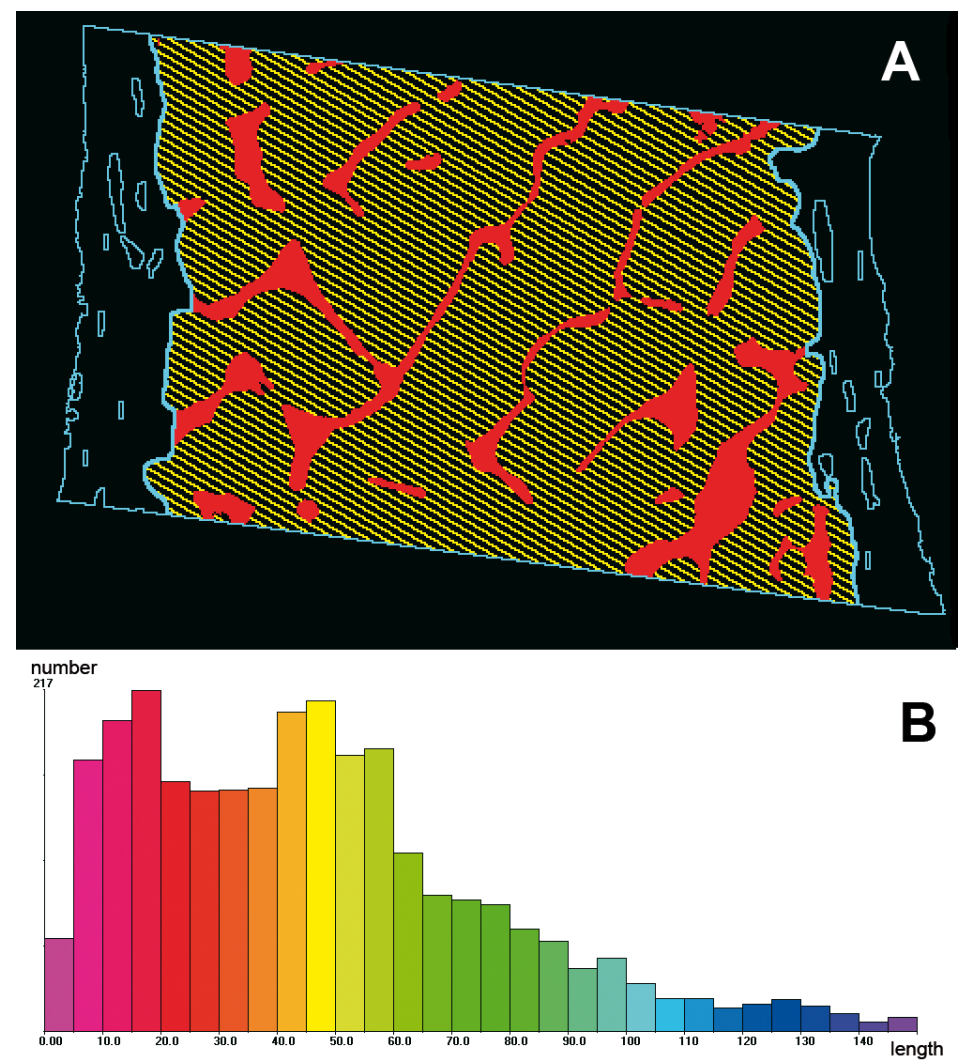

Fig. 3 Microarchitecture of bone section studied by image analysis; star volume determined by the chordlength method [57](A) with frequency distribution of the chords $(B)$.

\section{Microcomputed tomography (microCT), nanoCT and synchrotron: histomorphometry in \\ 3D}

With the development of microcomputers, new instruments have appeared during the last decade and provide a 3D histomorphometric analysis of bone. MicroCT came as the first laboratory available method to allow a fast ex vivo exploration and 3D measurements of bone samples [5859]. The equipments have now a resolution better than $10 \mu \mathrm{m} / \mathrm{voxel}$, the cone beam or spiral acquisition mode are favored and provide realistic images similar to SEM but are non destructive for the samples. The systems are composed of a sealed microfocus X-ray tube and a CCD camera. Specimens can be studied either in the wet or dry form. For each specimen, a series of projection images are obtained with a rotation angle between each image. A stack of 2D sections is reconstructed from the projection images and 3D reconstruction of objects is obtained after interactive thresholding. The 3D models can be obtained by using a volume or a surfacerendering algorithm (surface rendering is more adapted to bone) (Figure 4). MicroCT is now available for in vivo analysis of small animals. pQCT allows the analysis of bone microarchitecture at the peripheral bones (radius and tibia) of patients with osteoporosis [60]. 
The synchrotron is also an interesting tool (voxel size in the order of $1 \mu \mathrm{m}$ ) but remains a very limited technique due to high cost and poor accessibility [61]. New microCT and nanoCT are now on the market with approximately the same resolution than synchrotron. These systems allow the measurement of bone volume and trabecular characteristics directly in 3D and new indices have been developed (structure model index, frequency distribution of thickness, connectivity density... ). They provide realistic images of the microarchitecture of trabecular bone which helped to identify specific aspects in osteoporosis and malignant bone diseases [53, 62]. However, microCT is only its beginnings and there is yet no standardization of parameters between manufacturers. Furthermore, discrepancies exist when comparing thickness parameters in human bone with results obtained by histomorphometry on 2D sections [62-64]. We have shown that the shape of the measured objects themselves can strongly influence the results, leading to erroneous conclusions [65].

A

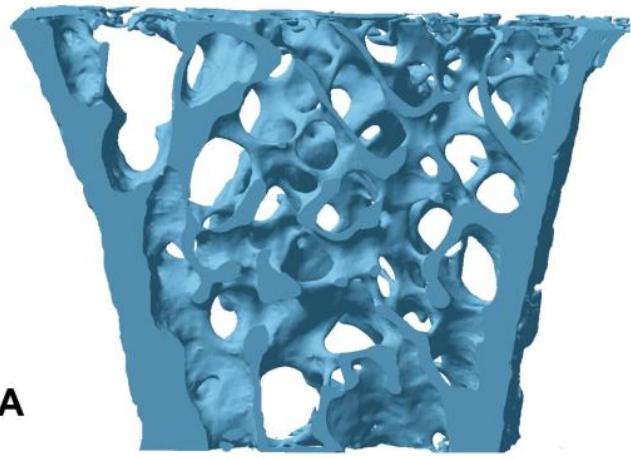

B

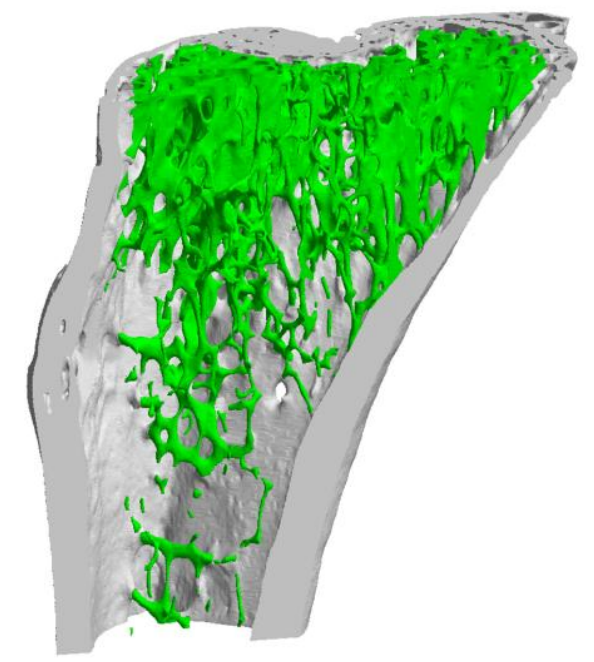

Fig. 4 MicroCT image of a human transiliac bone biopsy with surface rendering used to reconstruct the 3D model (A) and a mouse tibia with a glucocorticoid induced osteopenia (trabecular bone in green, cortical bone in grey).

\section{Microradiography}

The method was proposed many years ago when it was one of the only methods to study bone and teeth [66-68]. The technique is based on the absorption of X-rays by the mineral phase of the bone matrix. The images are obtained with prolonged exposition times and a X-ray tube working at $20-25 \mathrm{kV}, 20-25 \mathrm{~mA}$ and a nickel or beryllium window is used for filtering. The degree of mineralization varies among the different BSUs: the newly deposited ones are less calcified than the oldest or than in the interstial bone [69-70]. The older are the BSUs, the higher is their load in hydroxyapatite since they are more advanced in the secondary mineralization phase. The method has found a new interest to show that bisphosphonates (and more generally speaking antiresorptive agents) induced a uniform mineralization degree of BSUs [71]. The method 
provides sharply-defined images that allow quantitative analysis but, nowadays microradiography is difficult to develop due to the limited availabilyt of the suitable X-ray films. Scanning electron microscopy (SEM) in the backscattered energy mode (BSE) can provide similar results.

\section{Scanning election microscopy: not only a microscope to see in 3D}

SEM was the first method used to evaluate bone microarchitecture. The classical SEM image is produced by collecting secondary electrons that are ejected from the atoms of the sample surface by inelastic interaction with the electron beam. The first 3D images of trabeculae were presented by Whitehouse [72]. Although SEM is unique to image bone architecture and details of the trabecular surfaces, the method is destructive for the samples; furthermore SEM uses cavalier perspective and measurements are not possible (Figure 5A).

In the BSE mode, the high-energy electron coming from the incident beam are reflected by elasting scattering interactions with the sample atoms. The atoms with a high atomic number backscatter electron more strongly than those with a lower number and they appear brighter on the SEM image. The BSE mode in SEM was developed by Boyde and Jones as an alternative to microradiography [73] and found suitable to quantify the Bone Mineral Density Distribution (BMDD) of the BSUs [74]. The method is based on the measurement of the gray level in the image of a polished bone block embedded in poly methylmethacrylate. As the degree of mineralization depends on the bone remodeling rate, newly formed BSUs are less mineralized than old ones (Figure 5B). The BMDD studies these variations after a suitable calibration of the SEM detector [74]. SEM in the BSE identifies calcium in hydroxyapatite crystals, the amount of unbound calcium in osteoid is too low to be detected [75]. BMDD is usually a normal (i.e., Gaussian curve). Antiresorptive treatments which reduce bone turnover, displace the curve on the right (higher mineral densities) while an accelerated bone turnover (observed in primary hyperparathyroidism) reduces the degree and homogeneity of the bone matrix mineralization
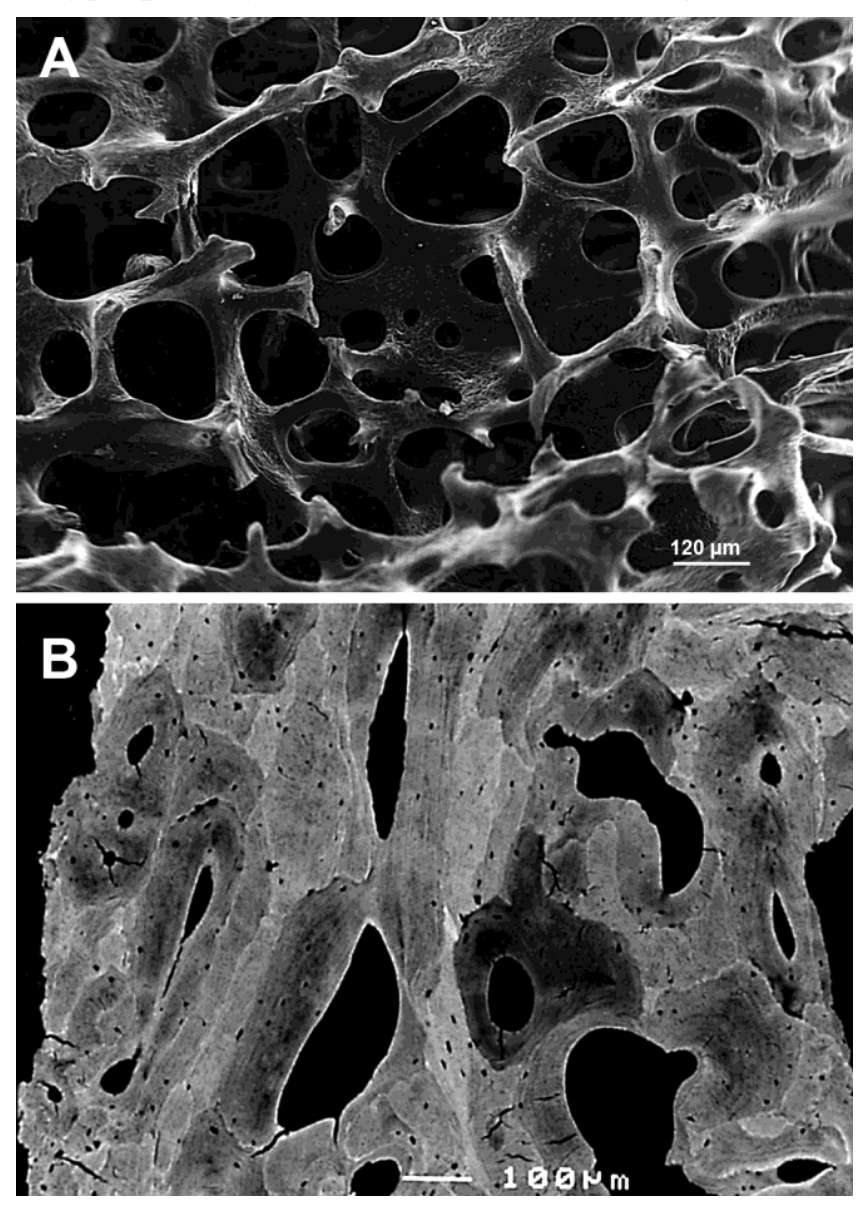

[76]. A linear correlation of the mineralization degree of BSUs has been found with nanoindentation values in human bone [77].

Fig. 5 SEM imaging of bone. A) Secondary electron mode shown the microarchitecture of trabecular bone, note the eroded surfaces on the trabeculae. B) Backscattered electron imaging of a polished human cortice showing the different BSU with various gray levels depending on their mineralization degree. 


\section{Fourier transformed infra-red (FTIR) and Raman: multispectral microscopies}

FTIR and Raman microscopy are two vibrational and complementary techniques capable of identifying mineral and collagen characteristics of the bone matrix. The molecules are excited by a monochromatic light beam. An IR diode is used for FTIR and a laser for Raman microspectroscopy. The photons interact with the molecules of the sample and these exited molecules respond by emission frequencies that depend on the masses of constituting atoms and on the strength of inter-atomic bonds. Thus each of the different bonds (for example $\mathrm{C}-\mathrm{H}$, $\mathrm{C}=\mathrm{C} \ldots$ ) is characterized by specific frequencies. They also depend on geometrical arrangement of atoms in molecules.

FTIR is usually done on thin sections of undecalcified bone embedded in poly methylmethacrylate and observed by transmission. The use of a multi detector permits the acquisition of a raster of spectra that can be used to provide an image; the method being known as FTIRI. Raman spectra are measured by epi-illuminating a slab or a block of bone embedded in poly methylmethacrylate with a laser and looking at vibrations emerging from the specimen. The spot can be focalized onto the surface of the bone and wet specimens can be used. The classical microscopes cannot acquire multiple spectra at the same time and images must be obtained by spatial mapping. However, new generations of machines are coming on the market.

In both types of methods, the spectrum is composed of several sharp peaks; the energy shift between these peaks is equal to the vibrational frequency (Figure $6 \mathrm{~A}-\mathrm{B}$ ). The shape of these bands can be used as a chemically sensitive signature of the specimen. As bone contains various compounds (e.g., collagen, hydroxyapatite), the relative intensity of the peaks reflects the abundance of the components. The position of amides bands coming from the collagen can be observed together with peaks coming from the mineral phase (phosphates and carbonates) but their position varies between the two techniques. Figure 5 illustrates the differences between a typical spectrum of trabecular bone observed by Raman and FTIR. Images of a given peak can be obtained; Figure 6C illustrates the distribution of the phosphate and amide by FTIRI in the same trabeculae. In addition to these multispectral images, a number of derived parameters have been described and can be used to generate new images: in vibrational microscopy, the ratio of two peak intensities is proportional to the relative amounts of the two corresponding species. Several indexes have been proposed such as the mineral to matrix ratio [78-79], crystallinity of the mineral phase [80] and the type-B carbonate substitution, (the substitution of carbonate ions in locations of phosphate ions in the hydroxyapatite crystal) [81]. As bone matures, the size of the individual mineral crystal was found to increase [82]. Collagen maturity can be calculated from the ratio of pyridinium and deH-DHLNL collagen cross-links [29, 83]. 

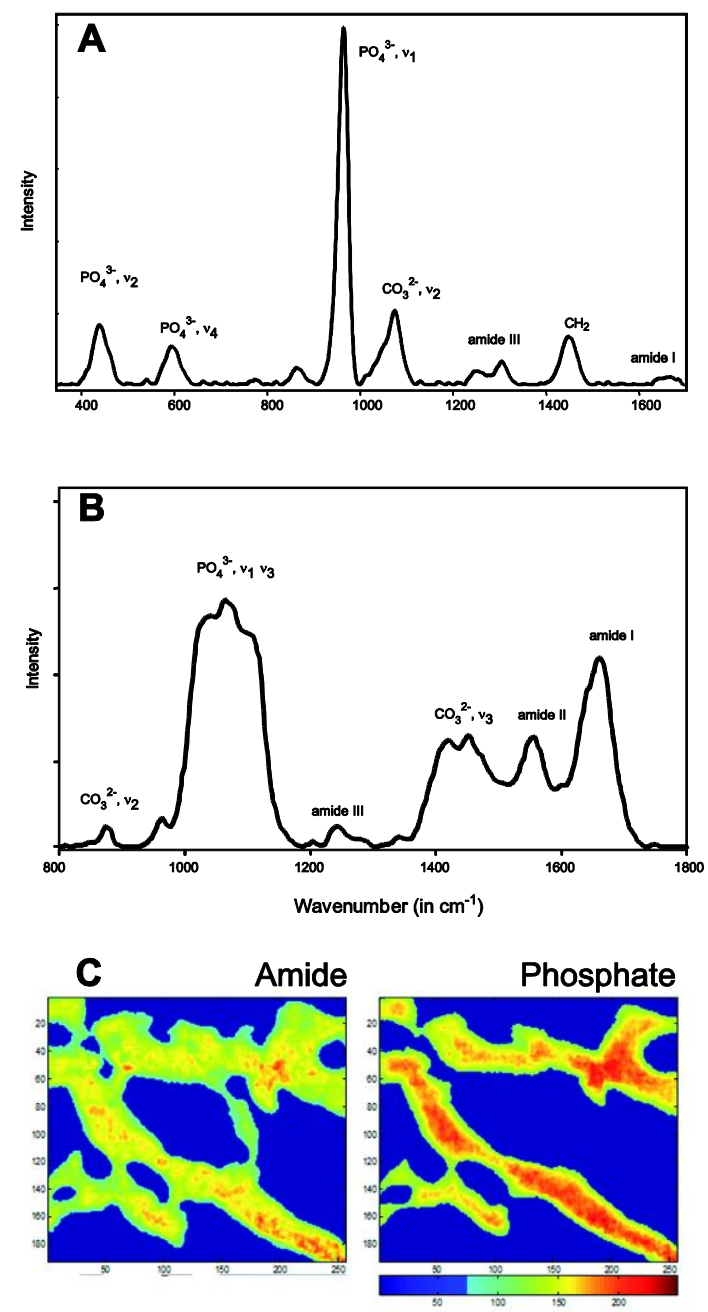

Fig. 6 Vibrational microscopy, Raman and FTIR. A) Spectrum of human bone obtained by Raman microspectroscopy and B) by FTIR. Note the position of the different peaks corresponding to the mineral (phosphate and carbonate) and the organic phase (amides of the collagen). C) FTIRI of the same section from a patient with osteomalacia. The amide image on the left reveals all the bone matrix territories while the phosphate image describes only the calcified areas.

\section{Scanning Acoustic Microscopy (SAM)}

This type of microscopy uses a ultrahigh frequency ultrasound beam which is focused onto the surface of a polished section of bone [84]. A fraction of the acoustic wave is reflected and captured by a sapphire lens. The beam scans the surface of the object and the resulting image is based on the variation in velocity of the ultrasound inside the bone matrix. The gray levels of the image reflect the elastic modulus of the different BSUs of the bone matrix. The system was used on cortical and trabecular bone; images were always compared to microradiography or SEMBSE for relating data with the mineralization degree [84-86]. Areas with low mineral density (newly formed BSUs or the cement lines around the osteons) have a lower value in SAM.

\section{Micro and nanoindentation}

Characterization of the biomechanical properties of bone as a living biomaterial is important in understanding the behavior of the tissue and have helped to clarify several pathophysiological mechanisms leading to fractures. Micro and nanoindentation are both 
hardness testing techniques based in the same principle: a pyramidal diamond probe (usually Vicker's for microindentation or Berkowitch's for nanoindentation) is applied onto a polished bone surface during a predetermined time with a known load. This produces hardness impressions with depth varying according to the material's properties. After the load is removed, the impression diagonal or width are measured and the hardness is derived depending on the geometry of the diamond probe (Figure 7). Microdurometry provides results at the bone level. Nano indentation is an effective technique to probe the biomechanical properties at the microscale and can be used to obtain hardness, Young's modulus, dissipated energy... The method has been extensively used to characterize the Young's modulus of cortical and trabecular bone [87-91]. A long term strontium ranelate treatment in the rat induced noticeable changes in the biomechanical properties identified by nanoindenation (maximal load, total energy and plastic energy) [92]. When combined with quantitative backscattering electron imaging, the method suggested that the organic phase of the bone matrix became stiffer in patients with femoral neck fracture [93]. Microindentation also found that the degree of mineralization is correlated with the Young's modulus [70]. However, the method measures the biomechanical properties at the tissue level and this does not always correlate with the stiffness of the entire bone sample [94].
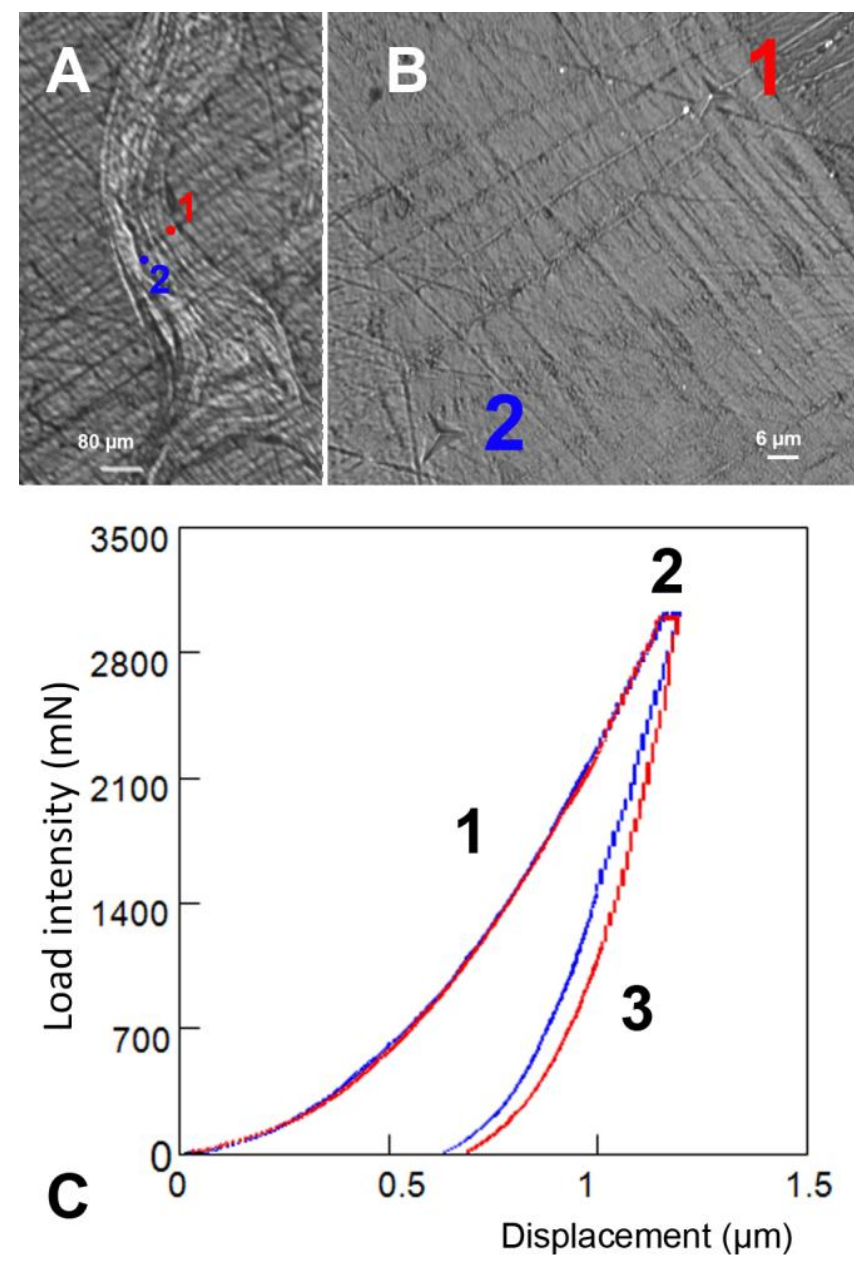

Fig. 7 Nanoindentation on a section of bone trabeculae. A) The trabecula is epi-illuminated and the position of the impact of the Berkowitch diamond is illustrated in 1) a "young" BSU in red, 2) interstitial bone in blue. B) Higher magnification of the impacts showing the pyramidal indentations. C) Curve illustrating the different time period recorded during indentation. The $1^{\text {st }}$ part of the curve is obtained when the load is applied and the probe penetrates the material. It is a combination of elastic properties and deformation. When the maximum load is reach $\left(2^{\text {nd }}\right.$ plateau phase), the creeping deformation (plasticity) can persist around the diamond probe. The $3^{\text {rd }}$ part of the curve is obtained when the probe 
is retracted; it is considered to reflect elastic properties of the sample. The dissipated energy is the grey area between the curves. Note the differences between the stiffer curve in 2 vs. 1 .

\section{Atomic Force Microscopy (AFM)}

AFM is a high-resolution scanning probe microscopy which is able to show details at the molecular and atomic levels. AFM measures the forces acting between a fine tip (attached to a cantilever) and a sample surface. Attractive or repulsive forces due to the interaction of the tip and the material surface will provoke a positive (resp. negative) bending of the cantilever which is detected by a laser beam reflected on the back of the cantilever and collected by a photodiode. Interestingly, the tip can be loaded with an antibody to identify antigenic sites. Images are obtained by scanning the surface of the object. AFM has been used to characterize the surface of bone trabeculae showing the collagen bundles and the hydroxyapatite crystals [95-96]. It has also been found useful, combined with SEM, to analyze the changes in quality of bone allografts purified by various chemical processes [97]. However, the method can only examine very limited and plane surfaces.

\section{Finite Element Analysis (FEA)}

FEA consists of a dynamic computer model of an object that is stressed (e.g., examined under compression or traction) to analyze its specific characteristics. The method is largely used in new industrial products prior to manufacturing; orthopedic or dental implants are frequently evaluated by this method. The 3D models obtained by FEA use a complex system of points (nodes) that are combined to form a mesh. The mesh is enriched by entering in the program the biomechanical properties which define the object submitted to loading conditions. Nodes are distributed at certain density throughout the object and highly stressed areas have a larger number of nodes. The mesh can be compared to a web that can be deformed under the load. The method can be used to predict the behavior of bone when stresses are applied and shows the fragile areas succeptible to fracture. FEA can be used to reconstruct models from MRI, CT, pQCT or microCT data. For example, the effect of PTH treatment can be evaluated both at the whole bone level by [98] or by reconstructing the trabecular network from treated animals [99]. Because the method is non-destructive, several simulations can be done. In patients with hip fracture, a significant decrease in transverse stiffness of hip trabeculae (due to the resorption of connecting rod-like trabeculae) was found while the Young's modulus in compression did not differ from controls [100]. Recent developments have been done to identify the precise role of the trabecular rods and plates and their respective role by using microFEA techniques with new algorithms [101]. By using a design space optimization algorithm, it was possible to produce an realistic model that predict bone adaptation to mechanical usage in the proximal femur [102]. The technique was also used on peripheral quantitative images from post-menopausal women [103]. There are several limitations to the technique: mathematical models and algorithms are only approximation of the real world; the element material properties are assumed to be isotropic, linear elastic, and uniform with a fixed Young's modulus [104]. Clearly, as evidenced by other techniques, the BSUs are highly heterogenous and this can strongly affect some results.

\section{Miscellaneous histological methods}

Osteocytes are fragile cells with $\sim 50$ processes running in canaliculi of the matrix. These cells are embedded in the bone matrix and act as mechanoreceptors capable of detecting strains and initiating remodeling in damaged areas. They form a lacelike communicating network. These cells are very sensitive to heat, anoxia and glucocorticoids which can induce apotosis. The quality of the bone matrix appears mainly controlled by this "monitoring" cell network and death 
of osteocytes in a bone territory equals the death of the bone. Tunel staining has been proposed to identify the apoptotic osteocytes [105] and imunohistochemistry with caspase antibodies can also be used [7]. The traumatic section of the osteocyte processes by microcracks or microfractures has been found by block staining with basic fuchsin which stains the cell body and processes [106]. The highly fluorescent dye Hoechst 33342 can be used on undercalcified section to identify all living osteocytes [53]. Silver staining have been recognized to stain the walls of the ostocyte lacunae, the canaliculi and the cement lines. In an acidic medium, silver staining specifically identify osteopontin [107-108]. The method was found interesting to study the bone repair after experimental fracture [109].

Some other histological methods can bring interesting data. Polarization microscopy can identify woven bone in Paget's bone disease, fluorosis or other bone metaplasia. The use of picro Sirius
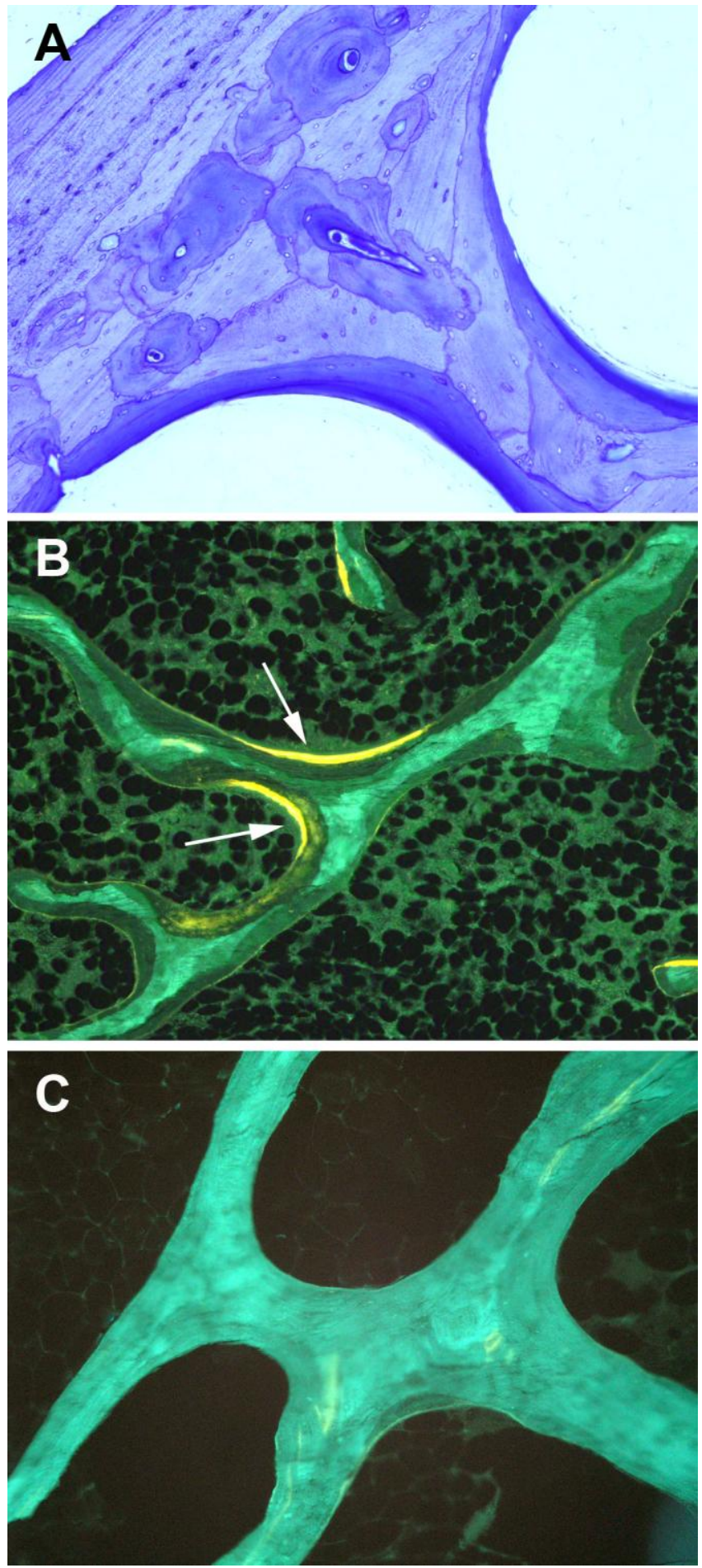
red $\mathrm{F} 3 \mathrm{~B}$ is known to increase collagen birefringence by a factor of 200, thus facilitating the identification of texture abnormalities. Surface-staining of thick undecalcified bone slabs is commonly used to study the biocompatibility of biomaterials (metallic or ceramic implants) which cannot be sectioned by heavy duty microtomes. It has been recognized that surface-staining of polished sections with toluidine blue borax demonstrates differences in blue intensity: newly-formed BSUs are more heavily stained than "old ones" (Figure 8A) [110]. The method was controlled by SAM and microradiography and the staining intensity negatively correlates with the degree of mineralization [111]. The staining does not work on thin microtome sections, and it is likely that the large amount of the poly methylmethacrylate remaining in polished sections limits the access of the stain since decalcified bone embedded similarly is uniformely and deeply stained.

Fig. 8 A) Surface staining with toluidine blue borax of the cortical bone from a rabbit. Note the differences in the intensity of blue staining of the BSUs: the youngest are stained in deep blue, the oldest are more faintly stained. B) Fluorescence microscopy of trabeculae in a human transiliac bone biopsy. Autofluorescence is low in the newly formed BSUs (in particular those with a double tetracycline label -arrowed) and high in the interstitial bone. C) Trabeculae from a patient having received alendronate during 3 years. Note the uniformity of autofluorescence in all the BSUs. 
Fluorescence microscopy with an adapted dichroic mirror (e.g. the Olympus U-MWBV2 cube) also appears able to identify differences in the autofluorescence of the BSUs on $14 \mu \mathrm{m}$ thick sections. The method was described many years ago but was not sufficiently exploited at that time [112] (Figure 8B-C). Because decalcification of the section does not influence autofluorescence intensity, it is likely that differences come from the collagen (probably the collagen cross-links which are known to be fluorescent at these wavelengthes). Vertical scanning profilometry is a newly developped method for non-contact optical measurement of roughness in material samples. The microscope produces topography maps of the sample surface. A light source is emitted and split into two beams which pass through a Mirau's interferometric objective. The incident beams are reflected from the reference mirror and the sample surface respectively. The light reflected from this mirror combines with the light reflected from the sample to produce interference fringes (known as interferogram); where the best-contrasted fringe occurs at best focus. The system can measure large surfaces thanks to the possibility to combine multiple overlapping fields of view (stitching). The volume of eroded surfaces caused by osteoclasts can be measured accurately [113]; the comparison of dry and wet polished bone samples illustrates the swelling properties of collagen which are more intense in less-mineralized areas (Figure 9) [114].

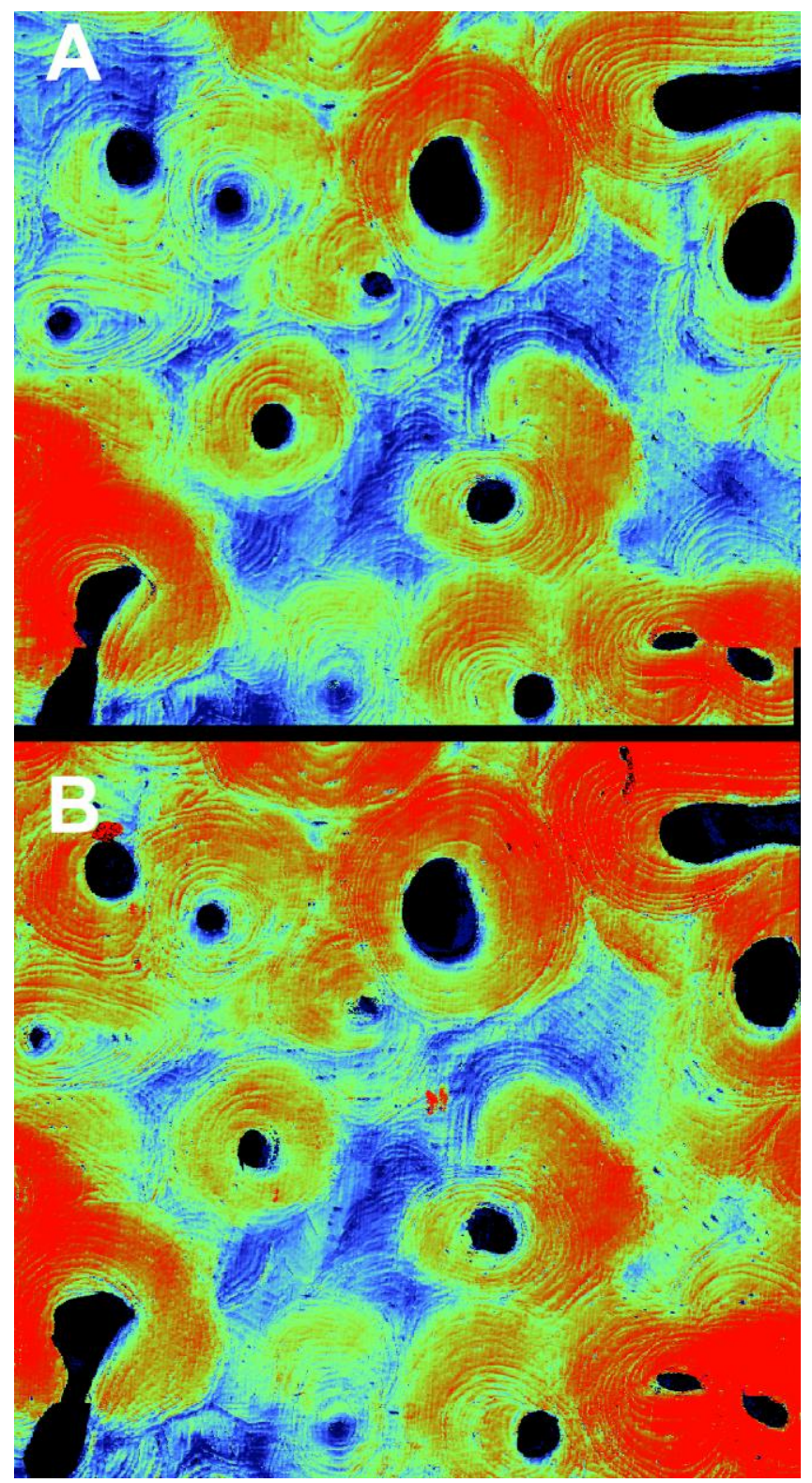

Fig. 9 Vertical scanning profilometry of a polished bone section of human femoral cortex examined dry $(A)$ (the blue areas are at the lower position, the red at the top) and after rehydration (B) Note the swelling of the most recent osteons (in red) while interstitial bone which is more calcified has a limited capacity to swell and remain blue. 


\section{Conclusion}

Methods for measuring bone quality are actually numerous and can investigate one or more components of the intricate factors that have been identified at that time [115]. The list of methods summarized here is certainly incomplete since more sophisticated techniques can be proposed for a finer study of the bone matrix at the hydroxyapatite crystal level or at the biochemical level. Nevertheless, all have in common the capacity to show that bone, as a material is highly heterogenous on a tissular level. This heterogeneity allows bone to resist to mechanical stresses by combining structure units with different elastic and stiffness properties. An altered bone turnover can influence one or more of the characteristics of the bone matrix (nature, texture, structure, microarchitecture and macroarchitecture) thus influencing the bone's resistance to fracture.

\section{Acknowledgments}

This work was made possible by grants from INSERM and Contrat Région Pays de la Loire (Bioregos2 program). Authors thank Mrs. Florence Pascaretti, Christine Gaudin, Nadine Gaborit, Guénaelle Brossard and Robert Filmon for skilful assistance with the histological techniques and Scanning Electron Microscopy. SEM analysis was done at SCIAM (Service Commun d'Imagerie et Analyses Microscopiques), Université d'Angers.

\section{References}

1. Kanis JA, Johnell O, Oden A, Johansson H, McCloskey E (2008) FRAX and the assessment of fracture probability in men and women from the UK. Osteoporos Int 19:385-397

2. Miller PD, Siris ES, Barrett-Connor E, Faulkner KG, Wehren LE, Abbott TA, Chen YT, Berger ML, Santora AC, Sherwood LM (2002) Prediction of fracture risk in postmenopausal white women with peripheral bone densitometry: evidence from the National Osteoporosis Risk Assessment. J Bone Miner Res 17:2222-2230

3. Cummings SR, Bates D, Black DM (2002) Clinical use of bone densitometry: scientific review. JAMA 288:1889-1897

4. Marshall D, Johnell O, Wedel H (1996) Meta-analysis of how well measures of bone mineral density predict occurrence of osteoporotic fractures. BMJ 312:1254-1259

5. Sandor T, Felsenberg D, Brown E (1999) Comments on the hypotheses underlying fracture risk assessment in osteoporosis as proposed by the World Health Organization. Calcif Tissue Int 64:267-270

6. Schuit SC, van der Klift M, Weel AE, de Laet CE, Burger H, Seeman E, Hofman A, Uitterlinden AG, van Leeuwen JP, Pols HA (2004) Fracture incidence and association with bone mineral density in elderly men and women: the Rotterdam Study. Bone 34:195-202

7. Bouvard B, Legrand E, Audran M, Chappard D (2010) Glucocorticoid-induced osteoporosis: a review. Clin Rev Bone Miner Metab 8:15-26

8. Dahl N, Holmgren G, Holmberg S, Ersmark H (1992) Fracture patterns in malignant osteopetrosis (Albers-Schonberg disease). Arch Orthop Trauma Surg 111:121-123 
9. Silverman SL (2008) Paget disease of bone: therapeutic options. J Clin Rheumatol 14:299-305

10. Curtis JR, Westfall AO, Cheng H, Saag KG, Delzell E (2009) RisedronatE and ALendronate Intervention over Three Years (REALITY): minimal differences in fracture risk reduction. Osteoporos Int 20:973-978

11. Delmas PD, Li Z, Cooper C (2004) Relationship between changes in bone mineral density and fracture risk reduction with antiresorptive drugs: some issues with metaanalyses. J Bone Miner Res 19:330-337

12. Quandt SA, Thompson DE, Schneider DL, Nevitt MC, Black DM (2005) Effect of alendronate on vertebral fracture risk in women with bone mineral density T scores of -1.6 to -2.5 at the femoral neck: the Fracture Intervention Trial. Mayo Clin Proc 80:343-349

13. Meunier PJ, Chavassieux P (1985) L'histomorphométrie moyen d'évaluation de la masse osseuse. Rev Rhum Malad Osteo-Art 52:669-673

14. Parfitt AM, Matthews CHE, Villanueva AR, Kleerekoper M, Frame B, Rao DS (1983) Relationships between surface, volume and thickness of iliac trabecular bone in aging and in osteoporosis. Implications for the microanatomic and cellular mechanisms of bone loss. J Clin Invest 72:1396-1409

15. Chappard D, Alexandre C, Riffat G (1988) Spatial distribution of trabeculae in iliac bone from 145 osteoporotic females. Acta Anat 132:137-142

16. Fyhrie DP (2005) Summary - Measuring "bone quality". J Muscul Skel Neur Interact 5:318-320

17. Felsenberg D, Boonen S (2005) The bone quality framework: Determinants of bone strength and their interrelationships, and implications for osteoporosis management. Clin Ther 27:1-11

18. Wei J, Ducy P (2010) Co-dependence of bone and energy metabolisms. Arch Biochem Biophys 503:35-40

19. Barth HD, Launey ME, MacDowell AA, Ager III JW, Ritchie RO (2010) On the effect of $\mathrm{X}$-ray irradiation on the deformation and fracture behavior of human cortical bone. Bone 46:1475-1485

20. Launey ME, Buehler MJ, Ritchie RO (2010) On the mechanistic origins of toughness in bone. Ann Rev Mater Res 40:1

21. Chappard D, Baslé MF, Legrand E, Audran M (2008) Trabecular bone microarchitecture: A review. Morphologie 92:162-170

22. Chapurlat R, Chappard D ( 2009) L'ostéoporose, mieux la comprendre pour mieux la traiter. Wolters Kluwer, Lippincott Williams \& Wilkins, Rueil-Malmaison.

23. Roughley PJ, Rauch F, Glorieux FH (2003) Osteogenesis imperfecta-clinical and molecular diversity. Eur Cell Mater 5:41-77

24. Zioupos P (2001) Ageing human bone: Factors affecting its biomechanical properties and the role of collagen. J Biomater Appl 15:187-229

25. Blank RD, Baldini TH, Kaufman M, Bailey S, Gupta R, Yershov Y, Boskey AL, Coppersmith SN, Demant P, Paschalis EP (2003) Spectroscopically determined collagen Pyr/deH-DHLNL cross-link ratio and crystallinity indices differ markedly in recombinant congenic mice with divergent calculated bone tissue strength. Connect Tissue Res 44:134-142

26. Banse X, Devogelaer JP, Lafosse A, Sims TJ, Grynpas M, Bailey AJ (2002) Cross-link profile of bone collagen correlates with structural organization of trabeculae. Bone 31:7076

27. Saito M, Marumo K (2010) Collagen cross-links as a determinant of bone quality: A possible explanation for bone fragility in aging, osteoporosis, and diabetes mellitus. Osteoporosis Int 21:195-214 
28. Oxlund H, Mosekilde L, Ortoft G (1996) Reduced concentration of collagen reducible cross links in human trabecular bone with respect to age and osteoporosis. Bone 19:479484

29. Blouin S, Thaler HW, Korninger C, Schmid R, Hofstaetter JG, Zoehrer R, Phipps R, Klaushofer K, Roschger P, Paschalis EP (2009) Bone matrix quality and plasma homocysteine levels. Bone 44:959-964

30. Libouban H, Filmon R, Maureac A, Baslé MF, Chappard D (2009) Fetuin and osteocalcin interact with calcospherite formation during the calcification process of poly(2hydroxyethylmethacrylate) in vitro: a Raman microspectroscopic monitoring. J Raman Spectrosc 40:1234-1239

31. Holden JL, Clement JG, Phakey PP (1995) Age and temperature related changes to the ultrastructure and composition of human bone mineral. J Bone Miner Res 10:1400-1409

32. Iyo T, Maki Y, Sasaki N, Nakata M (2004) Anisotropic viscoelastic properties of cortical bone. J Biomech 37:1433-1437

33. Boivin G, Meunier PJ (2003) The mineralization of bone tissue: a forgotten dimension in osteoporosis research. Osteoporos Int 14 Suppl 3:S19-24

34. Gupta HS, Seto J, Wagermaier W, Zaslansky P, Boesecke P, Fratzl P (2006) Cooperative deformation of mineral and collagen in bone at the nanoscale. Proc Natl Acad Sci USA 103:17741-17746

35. Gorski JP (1998) Is all bone the same? Distinctive distributions and properties of noncollagenous matrix proteins in lamellar vs. woven bone imply the existence of different underlying osteogenic mechanisms. Crit Rev Oral Biol Med 9:201-223

36. Mulder L, Koolstra JH, den Toonder JM, van Eijden TM (2008) Relationship between tissue stiffness and degree of mineralization of developing trabecular bone. J Biomed Mater Res - Part A 84:508-515

37. Seeman E (2003) Periosteal bone formation--a neglected determinant of bone strength. N Engl J Med 349:320-323

38. Singh I (1978) The architecture of cancellous bone. J Anat 127:305-310

39. Bertram JE, Biewener AA (1988) Bone curvature: sacrificing strength for load predictability? J Theor Biol 131:75-92

40. Lanyon LE, Bourn S (1979) The influence of mechanical function on the development and remodeling of the tibia. An experimental study in sheep. J Bone Joint Surg Am 61:263-273

41. Boonen S, Koutri R, Dequeker J, Aerssens J, Lowet G, Nijs J, Verbeke G, Lesaffre E, Geusens P (1995) Measurement of femoral geometry in type I and type II osteoporosis: differences in hip axis length consistent with heterogeneity in the pathogenesis of osteoporotic fractures. J Bone Miner Res 10:1908-1912

42. Faulkner KG, Cummings SR, Black D, Palermo L, Gluer CC, Genant HK (1993) Simple measurement of femoral geometry predicts hip fracture: the study of osteoporotic fractures. J Bone Miner Res 8:1211-1217

43. Duan Y, Parfitt A, Seeman E (1999) Vertebral bone mass, size, and volumetric density in women with spinal fractures. J Bone Miner Res 14:1796-1802

44. Gilsanz V, Gibbens DT, Roe TF, Carlson M, Senac MO, Boechat MI, Huang HK, Schulz EE, Libanati CR, Cann CC (1988) Vertebral bone density in children: effect of puberty. Radiology 166:847-850

45. Bergot C, Bousson V, Meunier A, Laval-Jeantet M, Laredo JD (2002) Hip fracture risk and proximal femur geometry from DXA scans. Osteoporos Int 13:542-550

46. Karlamangla AS, Barrett-Connor E, Young J, Greendale GA (2004) Hip fracture risk assessment using composite indices of femoral neck strength: the Rancho Bernardo study. Osteoporos Int 15:62-70 
47. Seeman E (2008) Bone quality: The material and structural basis of bone strength. J Bone Miner Metab 26:1-8

48. Seeman E, Delmas PD (2006) Bone quality - The material and structural basis of bone strength and fragility. N Engl J Med 354:2250-2261

49. Genant HK, Jiang JY (2006) Imaging assessment of bone quality in osteoporosis. Clin Rev Bone Miner Metab 4:213-224

50. Benhamou CL, Lespessailles E, Jacquet G, Harba R, Jennane R, Loussot T, Tourliere D, Ohley W (1994) Fractal organization of trabecular bone images on calcaneus radiographs. J Bone Miner Res 9:1909-1918

51. Guggenbuhl P, Bodic F, Hamel L, Baslé MF, Chappard D (2006) Texture analysis of Xray radiographs of iliac bone is correlated with bone micro-CT. Osteoporos Int 17:447454

52. Frost HM (1976) A method of analysis of trabecular bone dynamics. In Meunier PJ (ed) Bone Histomorphometry - $2^{\text {nd }}$ Int Workshop. Armour Montagu Lab., Levallois-Perret, pp 445-476.

53. Chappard D (2009) Technical aspects: How do we best prepare bone samples for proper histological analysis? In Heymann D (ed) Bone cancer: progression and therapeutic approaches. Acad. Press; Elsevier Inc., London, pp 203-210.

54. Fazzalari NL, Parkinson IH (1996) Fractal dimension and architecture of trabecular bone. J Pathol 178:100-105

55. Tabor Z (2004) Analysis of the influence of image resolution on the discriminating power of trabecular bone architectural parameters. Bone 34:170-179

56. Chappard D, Legrand E, Haettich B, Chales G, Auvinet B, Eschard JP, Hamelin JP, Baslé MF, Audran M (2001) Fractal dimension of trabecular bone: comparison of three histomorphometric computed techniques for measuring the architectural two-dimensional complexity. J Pathol 195:515-521

57. Chappard D, Legrand E, Pascaretti C, Baslé MF, Audran M (1999) Comparison of eight histomorphometric methods for measuring trabecular bone architecture by image analysis on histological sections. Microsc Res Tech 45:303-312

58. Ruegsegger P (1994) The use of peripheral QCT in the evaluation of bone remodelling. The Endocrinol 4:167-176

59. Sasov A, Van Dyck D (1998) Desktop X-ray microscopy and microtomography. J Microsc 191:151-158

60. Rizzoli R, Laroche M, Krieg MA, Frieling I, Thomas T, Delmas P, Felsenberg D (2010) Strontium ranelate and alendronate have differing effects on distal tibia bone microstructure in women with osteoporosis. Rheumatol Int 30:1341-1348

61. Peyrin F, Muller C, Carillon Y, Nuzzo S, Bonnassie A, Briguet A (2001) Synchrotron radiation microCT: a reference tool for the characterization of bone samples. Adv Exp Med Biol 496:129-142

62. Chappard D, Josselin N, Rouge-Maillart C, Legrand E, Baslé MF, Audran M (2007) Bone microarchitecture in males with corticosteroid-induced osteoporosis. Osteoporos Int 18:487-494

63. Hordon LD, Itoda M, Shore PA, Shore RC, Heald M, Brown M, Kanis JA, Rodan GA, Aaron JE (2006) Preservation of thoracic spine microarchitecture by alendronate: Comparison of histology and microCT. Bone 38:444-449

64. Alexander JM, Bab I, Fish S, Müller R, Uchiyama T, Gronowicz G, Nahounou M, Zhao Q, White DW, Chorev M, Gazit D, Rosenblatt M (2001) Human parathyroid hormone 134 reverses bone loss in ovariectomized mice. J Bone Miner Res 16:1665-1673 
65. Chappard D, Retailleau-Gaborit N, Legrand E, Baslé MF, Audran M (2005) Comparison insight bone measurements by histomorphometry and microCT. J Bone Miner Res 20:1177-1184

66. Amprino R (1952) Rapporti fra processi di ricostruzione e distribuzione dei minerali nelle ossa. I. Ricerche esguite col metodo dis tudio dei raggi Roentgen. Z Zellforsch 37:144183

67. Jowsey J, Kelly PJ, Riggs BL, Bianco AJ, Scholz DA, Gershon-Cohen J (1965) Quantitative microradiographic studies of normal and osteoporotic bone. J Bone Joint Surg Am 47:785-872

68. Dhem A, Nyssen-Behets C, Coppens J (1998) Post-menopausal osteoporosis: microradiographic aspects. It J Anat Embryol 103:343-352

69. Boivin G, Meunier PJ (2002) The degree of mineralization of bone tissue measured by computerized quantitative contact microradiography. Calcif Tissue Int 70:503-511

70. Boivin G, Bala Y, Doublier A, Farlay D, Ste-Marie LG, Meunier PJ, Delmas PD (2008) The role of mineralization and organic matrix in the microhardness of bone tissue from controls and osteoporotic patients. Bone 43:532-538

71. Boivin GY, Chavassieux PM, Santora AC, Yates J, Meunier PJ (2000) Alendronate increases bone strength by increasing the mean degree of mineralization of bone tissue in osteoporotic women. Bone 27:687-694

72. Whitehouse WJ, Dyson ED, Jackson CK (1971) The scanning electron microscope in studies of trabecular bone from a human vertebral body. J Anat 108:481-496

73. Boyde A, Jones SJ (1983) Back-scattered electron imaging of skeletal tissues. Metab Bone Dis Relat Res 5:145-150

74. Roschger P, Fratzl P, Eschberger J, Klaushofer K (1998) Validation of quantitative backscattered electron imaging for the measurement of mineral density distribution in human bone biopsies. Bone 23:319-326

75. Corsi A, Collins MT, Riminucci M, Howell PGT, Boyde A, Gehron Robey P, Bianco P (2003) Osteomalacic and Hyperparathyroid Changes in Fibrous Dysplasia of Bone: Core Biopsy Studies and Clinical Correlations. J Bone Miner Res 18:1235-1246

76. Roschger P, Paschalis EP, Fratzl P, Klaushofer K (2008) Bone mineralization density distribution in health and disease. Bone 42:456-466

77. Smith LJ, Schirer JP, Fazzalari NL (2010) The role of mineral content in determining the micromechanical properties of discrete trabecular bone remodeling packets. J Biomech 43:3144-3149

78. Boskey AL, Camacho NP, Mendelsohn R, Doty SB, Binderman I (1992) FT-IR microscopic mappings of early mineralization in chick limb bud mesenchymal cell cultures. Calcif Tissue Int 51:443-448

79. Akkus O, Adar F, Schaffler MB (2004) Age-related changes in physicochemical properties of mineral crystals are related to impaired mechanical function of cortical bone. Bone 34:443-453

80. Paschalis EP, DiCarlo E, Betts F, Sherman P, Mendelsohn R, Boskey AL (1996) FTIR microspectroscopic analysis of human osteonal bone. Calcif Tissue Int 59:480-487

81. Penel G, Leroy G, Rey C, Bres E (1998) MicroRaman spectral study of the PO4 and CO3 vibrational modes in synthetic and biological apatites. Calcif Tissue Int 63:475-481

82. Boskey A (2003) Bone mineral crystal size. Osteoporosis Int 14:S16-S20

83. Paschalis EP, Verdelis K, Doty SB, Boskey AL, Mendelsohn R, Yamauchi M (2001) Spectroscopic characterization of collagen cross-links in bone. J Bone Miner Res 16:1821-1828

84. Katz JL, Meunier A (1993) Scanning acoustic microscope studies of the elastic properties of osteons and osteon lamellae. J Biomech Eng 115:543-548 
85. Regauer M, Jurgens P, Budenhofer U, Hartstock M, Bocker W, Burklein D, Mutschler W, Sader R, Schieker M (2006) Quantitative scanning acoustic microscopy compared to microradiography for assessment of new bone formation. Bone 38:564-570

86. Bumrerraj S, Katz JL (2001) Scanning acoustic microscopy study of human cortical and trabecular bone. Ann Biomed Eng 29:1034-1042

87. Olesiak SE, Oyen ML, Ferguson VL (2010) Viscous-elastic-plastic behavior of bone using Berkovich nanoindentation. Mechan Time-Dep Mater 14:111-124

88. Roy ME, Rho JY, Tsui TY, Evans ND, Pharr GM (1999) Mechanical and morphological variation of the human lumbar vertebral cortical and trabecular bone. J Biomed Mater Res 44:191-197

89. Rho JY, Roy ME, 2nd, Tsui TY, Pharr GM (1999) Elastic properties of microstructural components of human bone tissue as measured by nanoindentation. J Biomed Mater Res 45:48-54

90. Rho JY, Zioupos P, Currey JD, Pharr GM (1999) Variations in the individual thick lamellar properties within osteons by nanoindentation. Bone 25:295-300

91. Fan Z, Swadener JG, Rho JY, Roy ME, Pharr GM (2002) Anisotropic properties of human tibial cortical bone as measured by nanoindentation. J Orthop Res 20:806-810

92. Ammann P, Badoud I, Barraud S, Dayer R, Rizzoli R (2007) Strontium ranelate treatment improves trabecular and cortical intrinsic bone tissue quality, a determinant of bone strength. J Bone Miner Res 22:1419-1425

93. Fratzl-Zelman N, Roschger P, Gourrier A, Weber M, Misof BM, Loveridge N, Reeve J, Klaushofer K, Fratzl P (2009) Combination of nanoindentation and quantitative backscattered electron imaging revealed altered bone material properties associated with femoral neck fragility. Calcif Tissue Int 85:335-343

94. Silva MJ, Brodt MD, Fan Z, Rho JY (2004) Nanoindentation and whole-bone bending estimates of material properties in bones from the senescence accelerated mouse SAMP6. J Biomech 37:1639-1646

95. Zhao H, Jin H, Cai J, Ding S (2010) The process of collagen biomineralization observed by AFM in a model dual membrane diffusion system. Ultramicroscopy 110:1306-1311

96. Hassenkam T, Fantner GE, Cutroni JA, Weaver JC, Morse DE, Hansma PK (2004) Highresolution AFM imaging of intact and fractured trabecular bone. Bone 35:4-10

97. Dumas A, Gaudin-Audrain C, Mabilleau G, Massin P, Hubert L, Baslé MF, Chappard D (2006) The influence of processes for the purification of human bone allografts on the matrix surface and cytocompatibility. Biomaterials 27:4204-4211

98. Chevalier Y, Quek E, Borah B, Gross G, Stewart J, Lang T, Zysset P (2010) Biomechanical effects of teriparatide in women with osteoporosis treated previously with alendronate and risedronate: results from quantitative computed tomography-based finite element analysis of the vertebral body. Bone 46:41-48

99. Kim CH, Takai E, Zhou H, von Stechow D, Muller R, Dempster DW, Guo XE (2003) Trabecular bone response to mechanical and parathyroid hormone stimulation: the role of mechanical microenvironment. J Bone Miner Res 18:2116-2125

100. Homminga J, McCreadie BR, Ciarelli TE, Weinans H, Goldstein SA, Huiskes R (2002) Cancellous bone mechanical properties from normals and patients with hip fractures differ on the structure level, not on the bone hard tissue level. Bone 30:759-764

101. Saha PK, Xu Y, Duan H, Heiner A, Liang G (2010) Volumetric topological analysis: a novel approach for trabecular bone classification on the continuum between plates and rods. IEEE Trans Med Imaging 29:1821-1838

102. Boyle C, Kim IY (2011) Three-dimensional micro-level computational study of Wolff's law via trabecular bone remodeling in the human proximal femur using design space topology optimization. J Biomech DOI:10.1016/j.jbiomech.2010.1011.1029 
103. Liu XS, Cohen A, Shane E, Stein E, Rogers H, Kokolus SL, Yin PT, McMahon DJ, Lappe JM, Recker RR, Guo XE (2010) Individual Trabeculae Segmentation (ITS)-based morphological analysis of high-resolution peripheral quantitative computed tomography images detects abnormal trabecular plate and rod microarchitecture in premenopausal women with idiopathic osteoporosis. J Bone Miner Res 25:1496-1505

104. Cristofolini L, Schileo E, Juszczyk M, Taddei F, Martelli S, Viceconti M (2010) Mechanical testing of bones: The positive synergy of finite-element models and in vitro experiments. Philosophical Transactions of the Royal Society A: Mathematical, Physical and Engineering Sciences 368:2725-2763

105. Weinstein RS, Nicholas RW, Manolagas SC (2000) Apoptosis of osteocytes in glucocorticoid-induced osteonecrosis of the hip. J Clin Endocrinol Metab 85:2907-2912

106. Mori S, Harruff R, Ambrosius W, Burr DB (1997) Trabecular bone volume and microdamage accumulation in the femoral heads of women with and without femoral neck fractures. Bone 21:521-526

107. Gaudin-Audrain C, Gallois Y, Pascaretti-Grizon F, Hubert L, Massin P, Baslé MF, Chappard D (2008) Osteopontin is histochemically detected by the AgNOR acid-silver staining. Histol Histopathol 23:469-478

108. Pascaretti-Grizon F, Gaudin-Audrain C, Gallois Y, Retaillaud-Gaborit N, Baslé MF, Chappard D (2007) Osteopontin is an argentophilic protein in the bone matrix and in cells of kidney convoluted tubules. Morphologie 91:180-185

109. Kusuzaki K, Kageyama N, Shinjo H, Takeshita H, Murata H, Hashiguchi S, Ashihara T, Hirasawa Y (2000) Development of bone canaliculi during bone repair. Bone 27:655-659

110. Schenk RK, Olah AJ, Herrmann W (1984) Preparation of calcified tissues for light microscopy. In Dickson GR (ed) Methods of Calcified Tissue Preparation Elsevier, Amsterdam, pp 1-56.

111. Qin L, Hung L, Leung K, Guo X, Bumrerraj S, Katz L (2001) Staining intensity of individual osteons correlated with elastic properties and degrees of mineralization. $\mathrm{J}$ Bone Miner Metab 19:359-364

112. Prentice AI (1967) Autofluorescence of bone tissues. J Clin Pathol 20:717-719

113. Pascaretti-Grizon F, Mabilleau G, Baslé MF, Chappard D (2011) Measurement by vertical scanning profilometry of resorption volume and lacunae depth caused by osteoclasts on dentine slices. J Microscopy 241:DOI:10.1111/j.1365-2818.2010.03410.x

114. Chappard D, Pascaretti-Grizon F, Fontaine S, Mallet R, Filmon R, Baslé M, Mercier P (2009) Hydration of bone collagen is inversely related to mineral density as shown by vertical scanning microscopic interferometry. ASBMR abstract A09002775

115. Bouxsein ML (2003) Bone quality: where do we go from here? Osteoporos Int 14 Suppl 5:S118-127 